\title{
Consistency of tumor and immune cell programmed cell death ligand-1 expression within and between tumor blocks using the VENTANA SP263 assay
}

Paul Scorer ${ }^{1 *}$, Marietta Scott ${ }^{1}$, Nicola Lawson ${ }^{1}$, Marianne J. Ratcliffe ${ }^{2}$, Craig Barker ${ }^{1}$, Marlon C. Rebelatto ${ }^{3}$ and Jill Walker ${ }^{2}$

\begin{abstract}
Background: Several anti-programmed cell death-1 (PD-1) and anti-programmed cell death ligand-1 (PD-L1) therapies have shown encouraging safety and clinical activity in a variety of tumor types. A potential role for PD-L1 testing in identifying patients that are more likely to respond to treatment is emerging. PD-L1 expression in clinical practice is determined by testing one tumor section per patient. Therefore, it is critical to understand the impact of tissue sampling variability on patients' PD-L1 classification.

Methods: Resected non-small cell lung cancer (NSCLC), head and neck squamous cell carcinoma (HNSCC) and urothelial carcinoma (UC) tissue samples (five samples per tumor type) were obtained from commercial sources and two tumor blocks were taken from each. Three sections from each block ( $100 \mu \mathrm{m}$ apart) were stained using the VENTANA PD-L1 (SP263) assay, and scored based on the percentage of PD-L1-staining tumor cells (TCS) or tumor-infiltrating immune cells (ICS) present. Each section was categorized as PD-L1 high or low/negative using a variety of cut-off values, and intra-block and intra-case (between blocks of the same tumor) concordance (overall percentage agreement [OPA]) were evaluated. An additional 200 commercial NSCLC samples were also analyzed, and intra-block concordance determined by scoring two sections per sample ( $\geq 70 \mu \mathrm{m}$ apart).

Results: Concordance in TC PD-L1 classification was high at all applied cut-offs. Intra-block and intra-case OPA for the 15 NSCLC, HNSCC or UC samples were 100\% and 80-100\%, respectively, across all cut-offs; intra-block OPA for the 200 NSCLC samples was 91.0-98.5\% across all cut-offs. IC PD-L1 classification was less consistent; intra-block and intra-case OPA for the 15 NSCLC, HNSCC or UC samples ranged between 70 and 100\% and between 60 and 100\%, respectively, with similar observations in the intra-block analysis of the 200 NSCLC samples.

Conclusions: These results show the reproducibility of TC PD-L1 classification across the depth of the tumor using the VENTANA PD-L1 (SP263) assay. Practically, this means that treatment decisions based on TC PD-L1 classification can be made confidently, following analysis of one tumor section. Although more variable than TC staining, consistent IC PD-L1 classification was also observed within and between blocks and across cut-offs.
\end{abstract}

Keywords: PD-L1, Heterogeneity, Assay, Concordance, Consistency, Reproducibility, Immunohistochemistry, SP263, Intra-block, Intra-case

\footnotetext{
* Correspondence: Paul.Scorer@astrazeneca.com

'Precision Medicine Laboratories, Precision Medicine and Genomics, IMED Biotech Unit, AstraZeneca, HODGKIN, C/O B310 Cambridge Science Park, Milton Road, Cambridge CB4 OWG, UK

Full list of author information is available at the end of the article
}

(c) The Author(s). 2018 Open Access This article is distributed under the terms of the Creative Commons Attribution 4.0 International License (http://creativecommons.org/licenses/by/4.0/), which permits unrestricted use, distribution, and reproduction in any medium, provided you give appropriate credit to the original author(s) and the source, provide a link to the Creative Commons license, and indicate if changes were made. The Creative Commons Public Domain Dedication waiver (http://creativecommons.org/publicdomain/zero/1.0/) applies to the data made available in this article, unless otherwise stated. 


\section{Background}

Many tumors evade detection by the immune system by exploiting inhibitory pathways (checkpoints) that suppress antitumor responses [1]. Antibodies have been developed that target these checkpoints with the aim of restoring antitumor immune activity. One of the most promising targets is the programmed cell death-1 (PD-1) / programmed cell death ligand-1 (PD-L1) checkpoint pathway, which negatively regulates effector T-cell activity, inhibiting antitumor immune responses and thereby promoting tumor immune evasion $[2,3]$.

The anti-PD-1 therapies pembrolizumab and nivolumab and the anti-PD-L1 agents durvalumab, atezolizumab and avelumab have demonstrated antitumor activity and manageable safety profiles across different tumor types [4-15]. Evidence suggests that these types of therapies are associated with higher response rates in patients whose tumors have high PD-L1 expression compared to those with low/no PD-L1 expression $[4,5,10,16-18]$. Some of these agents are now available with companion or complementary PD-L1 diagnostic assays in various indications [19-22]; use of these assays aims to inform treatment decisions by identifying patients who are most likely to respond to treatment.

The clinical assessment of PD-L1 status relies on testing one formalin-fixed paraffin-embedded (FFPE) section per patient. Selection of a tumor section for biomarker analysis, including testing for PD-L1, may be random or dependent on factors such as sample quality or tumor tissue availability. Variations in the populations of PD-L1-staining tumor cells (TCs) and/or tumor-infiltrating immune cells (ICs) within a tumor could potentially impact the classification of the tumor as PD-L1-high or PDL1-low/negative.

Cellular architecture and IC infiltration can vary throughout the tumor; however, the impact of this on PD-L1 expression levels and, more importantly, the PD-L1 status used in assessing patient suitability for certain treatments, is not fully understood. A study by Rehman et al. investigating the heterogeneity of PD-L1 expression in non-small cell lung cancer (NSCLC) tumor samples showed variability in PD-L1 expression between fields of view on the same slide (91\% variance for TCs), but minimal heterogeneity between different blocks of the same tumor (94\% concordance for TCs) [23]. However, while the Rehman et al. study provides information about intra-section and intra-case heterogeneity, the variability within a single tissue block (intra-block) was not investigated.

Data on intra-block and intra-case concordance in PD-L1 classification are available for the VENTANA PD-L1 (SP142) assay, and the Dako PD-L1 IHC 28-8 PharmDx and PD-L1 IHC 22C3 PharmDx assays, in NSCLC and urothelial carcinoma (UC) tissue samples
[24-27]. The objective of our study was to assess the intra-block and intra-case concordance in PD-L1 staining of $\mathrm{TC}$ and $\mathrm{IC}$ populations using the VENTANA PD-L1 (SP263) assay. Tissue samples from NSCLC, head and neck squamous cell carcinoma (HNSCC) and UC were assessed.

\section{Methods}

Tumor samples, preparation and staining, and assessment of 15 NSCLC, HNSCC or UC samples

For this study, FFPE samples of resected tissue from primary NSCLC, HNSCC and UC tumors were obtained from commercial sources (Avaden Biosciences, Seattle WA, USA). Appropriate patient consents for sample use were in place. To ensure the sample cohort covered a wide range of PD-L1 TC expression, FFPE sections were acquired for 20 cases from each indication (60 cases in total) and stained with the VENTANA PD-L1 (SP263) assay. Five representative cases were then selected from each indication (15 cases in total). The 15 selected cases included six cases with PD-L1 expression in $>70 \%$ of TCs, six cases with PD-L1 expression in $20-50 \%$ of TCs, and three cases with little or no PD-L1 expression in TCs. This selection was performed independently, prior to circulation of the slides to the study pathologist. The 15 cases were selected primarily on TC content and PD-L1 expression in TCs; the IC content and PD-L1 expression in ICs were assessed for confirmation that ICs would be present for analysis. From the 15 cases entered into the study, 14 had PD-L1 expression in $<10 \%$ of ICs and one had PD-L1 expression in $>20 \%$ of ICs.

Following the initial screening, two large tumor resection blocks were taken from each case (30 blocks in total). The samples were sectioned serially at $4 \mu \mathrm{m}$ on to Superfrost Plus slides, dried at room temperature or $37^{\circ} \mathrm{C}$ overnight and then baked at $56{ }^{\circ} \mathrm{C}$ for $1 \mathrm{~h}$. Fifty-one serial sections were cut fresh from each block (Fig. 1) and cut sections were stored in slide storage boxes with close-fitting lids at $-20{ }^{\circ} \mathrm{C}$ until stained (within 1 month). Sections "Background" and 51 from each block were stained with hematoxylin and eosin to confirm that tumor was present in all serial sections, and to ensure there were enough TCs in the sections to provide an accurate estimate of PD-L1 expression. Sections "Methods", 25 and 50 from each block were stained using the VENTANA PD-L1 (SP263) assay with the VENTANA OptiView DAB IHC Detection Kit on the automated VENTANA BenchMark ULTRA platform. The sections were $\sim 100 \mu \mathrm{m}$ apart.

Stained sections were assessed by a single, certified pathologist, trained in PD-L1 immunohistochemistry interpretation (TCs and ICs) by VENTANA. To minimize bias, the pathologist was blind with respect to the case, block and section number being scored. The total percentage of TCs 


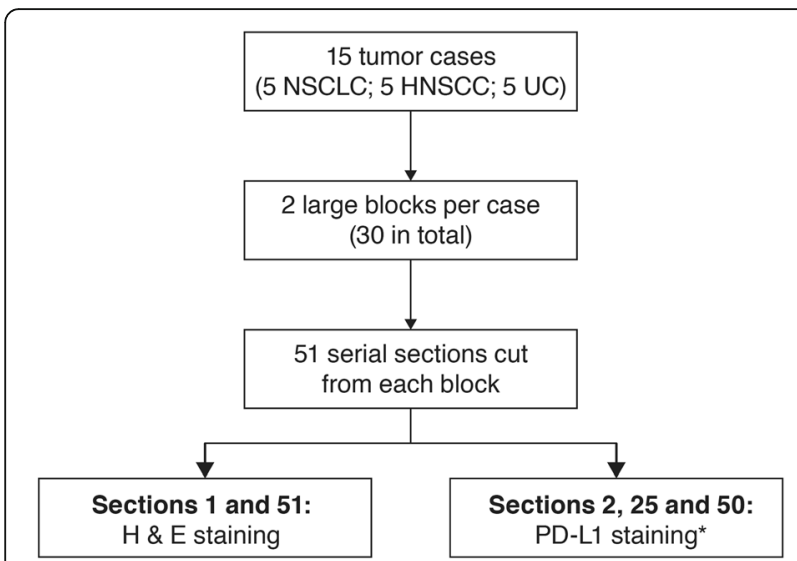

Fig. 1 Sample preparation from 15 NSCLC, HNSCC or UC cases. *Using the VENTANA PD-L1 (SP263) assay with the VENTANA OptiView DAB IHC detection kit on the automated VENTANA BenchMark ULTRA platform. H \& E: hematoxylin and eosin; HNSCC: head and neck squamous cell carcinoma; NSCLC: non-small cell lung cancer; PD-L1: programmed cell death ligand-1; UC: urothelial carcinoma

or ICs that stained positive for PD-L1 was recorded. Scoring of TC membrane positivity or IC positivity was performed as per the SP263 scoring algorithm and interpretation guide [28]. Scores of $>10 \%$ were recorded in $5 \%$ increments; scores of $\leq 10 \%$ were recorded as $<1 \%$; $1-4 \%$, 5-9 and 10\% (Fig. 2).

\section{Staining and assessment of additional 200 NSCLC samples} In addition to the 15 NSCLC, HNSCC or UC cases described above, 200 commercial NSCLC patient samples from Stage I-IV primary tumors (Asterand, MI, USA; ProteoGenex, CA, USA; Tissue Solutions, CA, USA) were available as part of a larger comparative study [29]. The methodology for preparation and assessment of these samples was published previously [29]. Fresh sections were cut from each block, 7 months apart, to simulate repeat testing in a clinical setting. The sections were cut at a minimum of $70 \mu \mathrm{m}$ separation, and were stained using the VENTANA PD-L1 (SP263) assay. These samples were read by a single blinded pathologist trained by VENTANA in a Clinical Laboratory Improvement Amendments (CLIA) program certified laboratory (Hematogenix, IL, USA). The mean washout period between assessments of the two sections from the same sample was 258 days (range 242-287). PD-L1 positivity was scored as follows: for TCs, scores of $>25 \%$ were recorded in $10 \%$ increments and scores of $\leq 25 \%$ were recorded as < $1 \%$; $1-4 \%, 5-9,10,20 \%$ or $25 \%$; for ICs, scores of $>10 \%$ were recorded in $10 \%$ increments and scores of $\leq 10 \%$ were recorded as $0,1,5 \%$ or $10 \%$.

\section{Statistical analysis: Intra-block and intra-case assessment of 15 NSCLC, HNSCC or UC samples}

For the 15 NSCLC, HNSCC or UC cases, TC and IC PD-L1 expression scores from the three sections of each block were recorded (90 TC and 90 IC scores in total; Additional file 1). Multiple clinically relevant diagnostic cut-offs (Table 1) [4, 8, 10-13, 17, 19-22, 30-33] were then applied to the TC and IC scores, and each section was classified as being above or below each cut-off value

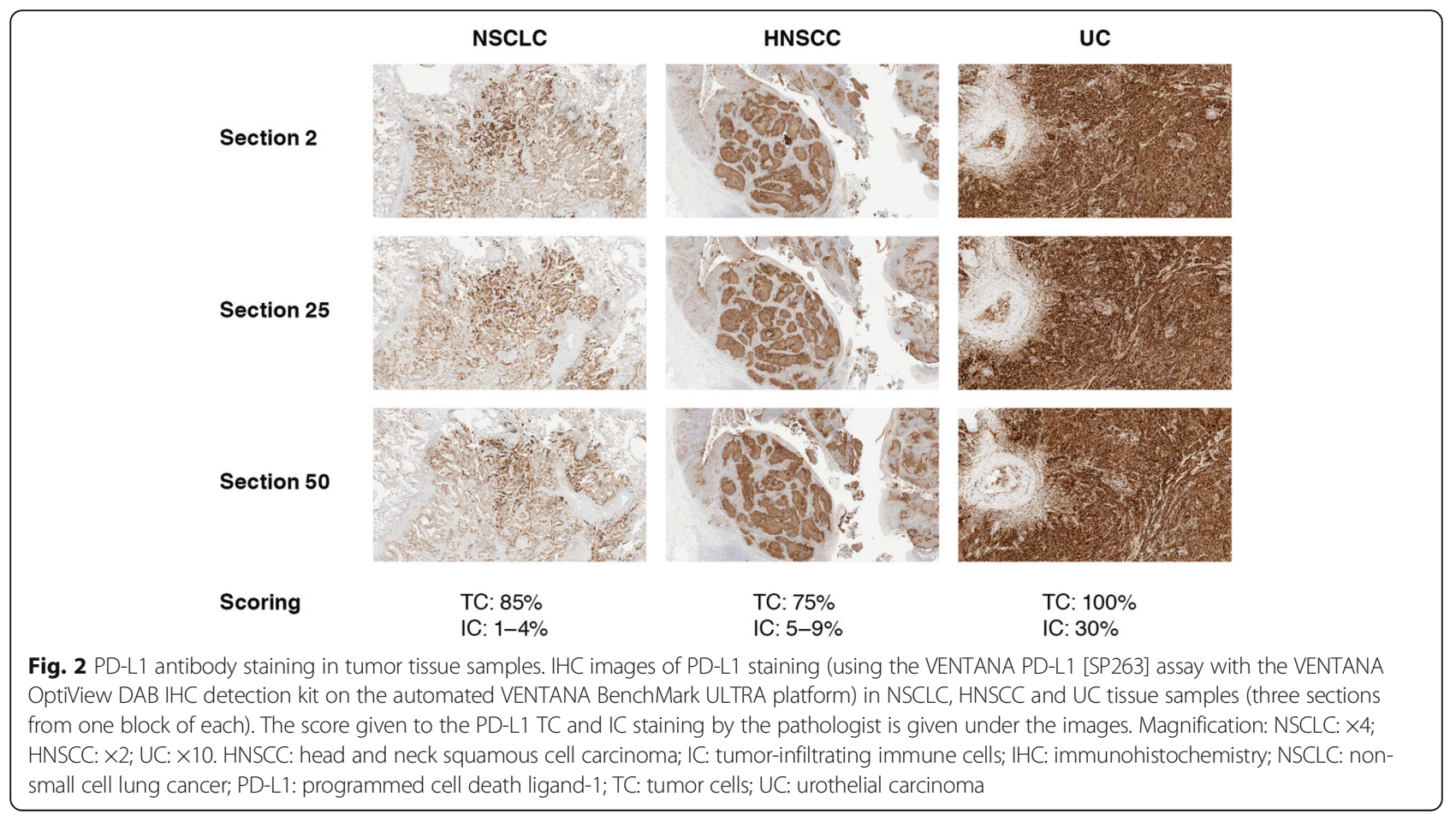


Table 1 Comparison of approved PD-L1 diagnostic assays and PD-L1 cut-offs in NSCLC, HNSCC and UC

\begin{tabular}{|c|c|c|c|c|}
\hline & VENTANA SP263 [19, 30] & Dako 22C3 [21] & Dako 28-8 [20] & VENTANA SP142 [22] \\
\hline $\begin{array}{l}\text { Developed as companion } \\
\text { diagnostic assay for: }\end{array}$ & $\begin{array}{l}\text { Durvalumab (AstraZeneca/ } \\
\text { Medlmmune) }\end{array}$ & $\begin{array}{l}\text { Pembrolizumab (Merck } \\
\text { Sharp \& Dohme) }\end{array}$ & $\begin{array}{l}\text { Nivolumab (Bristol-Myers } \\
\text { Squibb) }\end{array}$ & $\begin{array}{l}\text { Atezolizumab } \\
\text { (Genentech/Roche) }\end{array}$ \\
\hline Compartment & TC; TC or IC & $\mathrm{TC} ; \mathrm{TC} \& \mathrm{IC}$ & TC & TC or IC; IC \\
\hline PD-L1 cut-off NSCLC & $\geq 25 \%$ TC $[30]$ & $\begin{array}{l}\geq 50 \% \mathrm{TC}-1 \mathrm{~L}[21,31] \\
\geq 1 \% \mathrm{TC}-2 \mathrm{~L}[31]\end{array}$ & $\geq 1 \%, \geq 5 \%, \geq 10 \%$ TC $[8]$ & $\geq 50 \%$ TC or $\geq 10 \%$ IC $[13,22]$ \\
\hline PD-L1 cut-off HNSCC & $\geq 25 \%$ TC [30] & $\geq 1, \geq 50$ CPS $^{b}[17]$ & $\geq 1 \%, \geq 5 \%, \geq 10 \%$ TC $[10]$ & - \\
\hline PD-L1 cut-off UC & $\geq 25 \%$ TC or IC [4] & $\geq 10$ CPS $^{b}[32]$ & $\geq 1 \%, \geq 5 \%$ TC [11] & $\geq 5 \%$ IC $[12,22]$ \\
\hline FDA regulatory status & $\begin{array}{l}\text { Approved complementary } \\
\text { diagnostic in UC }\end{array}$ & $\begin{array}{l}\text { Approved companion } \\
\text { diagnostic in NSCLC }\end{array}$ & $\begin{array}{l}\text { Approved complementary } \\
\text { diagnostic in NSCLC }\end{array}$ & $\begin{array}{l}\text { Approved complementary } \\
\text { diagnostic in NSCLC and UC }\end{array}$ \\
\hline
\end{tabular}

aVENTANA SP263 is also approved for use with nivolumab and pembrolizumab in NSCLC patients (CE mark only; not FDA approved) [19]

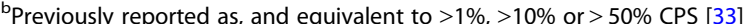

CPS combined positive score evaluating both TC and IC, HNSCC head and neck squamous cell carcinoma, IC tumor-infiltrating immune cell, NSCLC non-small cell lung cancer, PD-L1 programmed cell death ligand-1, TC tumor cell, UC urothelial carcinoma

(PD-L1 high or low/negative status, respectively). The applied cut-offs were: $\geq 50 \%, \geq 25 \%, \geq 10 \%$ and $\geq 1 \%$ for TCs; $\geq 25 \%, \geq 10 \%, \geq 5 \%$ and $\geq 1 \%$ for ICs.

A block was classified as discordant if there was any variation in the diagnostic results (PD-L1 status) for any of its three sections. Intra-case comparisons were the same as intra-block comparisons, with the exception that six sections in total were compared per case (three sections per block; two blocks per case). Overall percentage agreement (OPA) within blocks (intrablock) and between blocks (intra-case) was calculated at each cut-off.

\section{Statistical analysis: Intra-block analysis of 200 NSCLC cases} The analysis plan for the 200 NSCLC cases was published previously [29]. OPA, negative percentage agreement (NPA) and positive percentage agreement (PPA) [34] were calculated at multiple clinically relevant cut-offs ( $\geq 50 \%, \geq 25 \%, \geq 10 \%$ and $\geq 1 \%$ ) for the two sections from each block. For each metric, the lower boundary of the $95 \%$ confidence interval (CI) was calculated with no upper bound, using the Clopper-Pearson method [35].

\section{Results}

\section{Sample demographics}

The patient demographics for the 15 NSCLC, HNSCC or UC cases are presented in Table 2. Patient age at the time of surgery ranged between 49 and 82 years. The tumor samples analyzed were at different stages of disease; NSCLC: Stage IB-IIIA; HNSCC: Stage I-III; UC: Stage II-IV. Sample age at the time of analysis ranged from 1 to 13 years. The patient demographics for the 200 NSCLC samples have been presented previously [36]. Thirty-eight percent were Stage I, 36\% were Stage II and $21 \%$ were Stage III.

\section{Intra-block concordance in PD-L1 classification}

In the analysis of TCs, PD-L1 classification (above or below the cut-off) was consistent within tissue blocks for all the applied cut-offs (TC intra-block OPA was 100\%) (Table 3).

PD-L1 classification was less consistent in the analysis of ICs. IC intra-block OPA ranged between 70 and 100\% across all tumor types at the $\geq 1 \%, \geq 5 \%$ and $\geq 10 \%$ cut-offs. However, OPA was $100 \%$ across all tumor types at the $\geq 25 \%$ cut-off (Table 3), reflective of the fact that the majority $(14 / 15)$ of cases had IC staining scored below 25\% (Additional file 1). The percentage of PD-L1-staining ICs between sections of the discordant blocks varied by no more than one scoring category $(\sim 5 \%)$, and the differences in PD-L1 scoring were either: $<1 \%$ vs $1-4 \% ; 1-4 \%$ vs $5-9 \%$ or $5-9 \%$ vs $10 \%$ (Additional file 1).

These results were supported by the analysis of 200 additional NSCLC cases. In this much larger cohort, the minimum intra-block TC OPA was $91.0 \%$ (at the $\geq 1 \%$ cut-off); TC PPA and NPA were $>90$ and $>80 \%$, respectively, at all cut-offs (range: $81.4-100.0 \%$ across both PPA and NPA) (Table 4 and Fig. 3). The highest agreement was observed at the $\geq 25 \%$ cut-off (OPA: $98.5 \%$; PPA: 96.7\%; NPA: 100.0\%).

PD-L1 classification in ICs was less consistent across this larger sample set as well, with OPA values ranging from 78.5 to $95.5 \%$, across the different cut-offs (Table 4 and Fig. 3). This is also reflected in the PPA and NPA values; PPA values ranged from $14.3 \%$ (at the $\geq 50 \%$ cut-off) to $81.6 \%$ (at the $\geq 1 \%$ cut-off) and NPA values ranged from $77.1 \%$ (at the $\geq 1 \%$ cut-off) to $98.4 \%$ (at the $\geq 50 \%$ cut-off) (Table 4 and Fig. 3).

\section{Intra-case concordance in PD-L1 classification}

There was high agreement in TC PD-L1 classification between two different blocks from the same tumor; TC 
Table 2 Demographics of patients who provided samples for analysis

\begin{tabular}{|c|c|c|c|c|c|c|}
\hline Patient & Sample type & Sample age, years & $\begin{array}{l}\text { Patient age at } \\
\text { surgery, years }\end{array}$ & Sex & Primary diagnosis & Clinical stage \\
\hline \multicolumn{7}{|l|}{ NSCLC } \\
\hline 1 & Lung & 9 & 79 & Male & Squamous cell carcinoma & $\|$ \\
\hline 2 & Lung & 2 & 50 & Male & Squamous cell carcinoma & IIIA \\
\hline 3 & Lung & 1 & 82 & Male & Adenocarcinoma & $\| B$ \\
\hline 4 & Lung & 13 & 70 & Female & Adenocarcinoma & IB \\
\hline 5 & Lung & 13 & 71 & Male & Squamous cell carcinoma & $\| \mathrm{A}$ \\
\hline \multicolumn{7}{|l|}{ HNSCC } \\
\hline 6 & Tonsil & 10 & 64 & Female & Squamous cell carcinoma & I \\
\hline 7 & Tongue & 9 & 71 & Female & Squamous cell carcinoma & I \\
\hline 8 & Larynx & 6 & 55 & Male & Squamous cell carcinoma & III \\
\hline 9 & Tonsil & 6 & 49 & Female & Squamous cell carcinoma & I \\
\hline 10 & Tongue & 3 & 68 & Male & Squamous cell carcinoma & । \\
\hline \multicolumn{7}{|l|}{ UC } \\
\hline 11 & Bladder & 7 & 74 & Female & Urothelial cell carcinoma & III \\
\hline 12 & Bladder & 4 & 70 & Male & Urothelial cell carcinoma & $\|$ \\
\hline 13 & Bladder & 4 & 67 & Male & Urothelial cell carcinoma & IV \\
\hline 14 & Bladder & 3 & 80 & Female & Urothelial cell carcinoma & III \\
\hline 15 & Bladder & 3 & 82 & Male & Urothelial cell carcinoma & III \\
\hline
\end{tabular}

HNSCC head and neck squamous cell carcinoma, NSCLC non-small cell lung cancer, UC urothelial carcinoma

intra-case OPA was $100 \%$ across all tumor types and at all applied cut-offs except for NSCLC at the $\geq 50 \%$ cut-off, where OPA was $80 \%$ (Table 5).

Intra-case PD-L1 classification in the analysis of ICs was less consistent, with OPA values ranging from 60 to $100 \%$ across all tumor types at the $\geq 1 \%, \geq 5 \%$ and $\geq 10 \%$ cut-offs (Table 5). However, as with the intra-block analysis, intra-case OPA was $100 \%$ across all tumor types at

Table 3 Intra-block concordance (OPA) in PD-L1 classification at various applied cut-offs

\begin{tabular}{llll}
\hline $\begin{array}{l}\text { Applied } \\
\text { Cut-off }\end{array}$ & \multicolumn{3}{l}{ Concordance (OPA), \% } \\
\cline { 2 - 4 } & NSCLC & HNSCC & UC \\
\hline $\begin{array}{l}\text { TC PD-L1 staining } \\
\geq 50 \%\end{array}$ & 100 & 100 & 100 \\
$\geq 25 \%$ & 100 & 100 & 100 \\
$\geq 10 \%$ & 100 & 100 & 100 \\
$\geq 1 \%$ & 100 & 100 & 100 \\
IC PD-L1 staining & & & 100 \\
$\geq 25 \%$ & 100 & 100 & 100 \\
$\geq 10 \%$ & 70 & 90 & 80 \\
$\geq 5 \%$ & 90 & 100 & 80 \\
$\geq 1 \%$ & 100 & 100 &
\end{tabular}

Fifteen NSCLC, HNSCC or UC cases; 30 blocks in total (10 blocks per indication) HNSCC head and neck squamous cell carcinoma, $I C$ tumor-infiltrating immune cell, NSCLC non-small cell lung cancer, OPA overall percentage agreement, $P D-L 1$ programmed cell death ligand-1, TC tumor cell, UC urothelial carcinoma the $\geq 25 \%$ cut-off, again reflecting the lower levels of PD-L1 expression in ICs, compared with TCs.

\section{Discussion}

Clinical data suggest that anti-PD-1 / anti-PD-L1 treatment may be more effective in patients whose tumors have high expression of PD-L1 vs those with low/no expression of PD-L1 [4, 5, 10, 16-18]; as such, it is critical

Table 4 Intra-block concordance (OPA; PPA; NPA) in PD-L1 classification of NSCLC samples at various applied cut-offs

\begin{tabular}{|c|c|c|c|}
\hline Applied cut-off & $\begin{array}{l}\text { OPA } \\
\% \text { (lower 95\% Cl) }\end{array}$ & $\begin{array}{l}\text { PPA } \\
\% \text { (lower 95\% Cl) }\end{array}$ & $\begin{array}{l}\text { NPA } \\
\% \text { (lower 95\% Cl) }\end{array}$ \\
\hline \multicolumn{4}{|c|}{ TC PD-L1 staining } \\
\hline$\geq 50 \%$ & $97.0(94.2)$ & $92.2(84.3)$ & 99.3 (96.6) \\
\hline$\geq 25 \%$ & $98.5(96.2)$ & 96.7 (91.6) & $100.0(97.3)$ \\
\hline$\geq 10 \%$ & 96.5 (93.5) & $95.3(90.4)$ & $97.8(93.4)$ \\
\hline$\geq 1 \%$ & $91.0(86.9)$ & $96.2(92.1)$ & $81.4(72.1)$ \\
\hline \multicolumn{4}{|c|}{ IC PD-L1 staining } \\
\hline$\geq 50 \%$ & $95.5(92.3)$ & $14.3(0.7)$ & $98.4(96.0)$ \\
\hline$\geq 25 \%$ & 86.5 (81.9) & $17.9(7.3)$ & $97.7(94.8)$ \\
\hline$\geq 10 \%$ & $78.5(73.2)$ & 78.1 (71.9) & $79.6(67.8)$ \\
\hline$\geq 1 \%$ & 80.5 (75.3) & 81.6 (75.6) & $77.1(64.9)$ \\
\hline
\end{tabular}

200 NSCLC cases (two sections were scored for each case)

Cl confidence interval, IC tumor-infiltrating immune cell, NPA negative percentage agreement, NSCLC non-small cell lung cancer, OPA overall percentage agreement, $P D-L 1$ programmed cell death ligand-1, PPA positive percentage agreement, TC tumor cell 
TC PD-L1 staining ( $\mathrm{N}=\mathbf{2 0 0})$

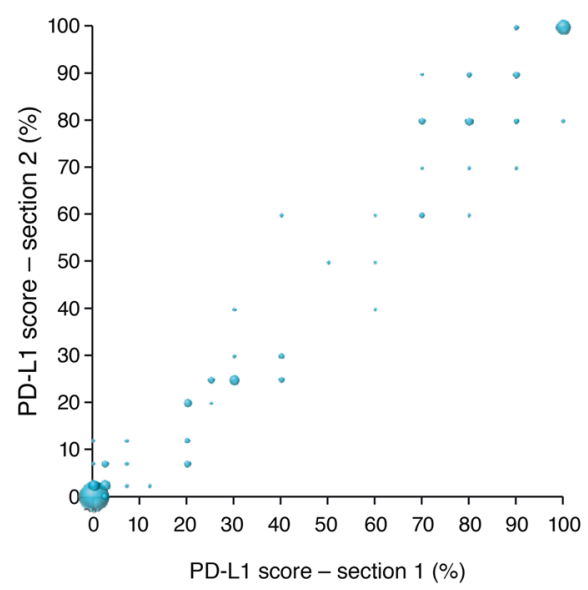

IC PD-L1 staining ( $\mathrm{N}=\mathbf{2 0 0})$

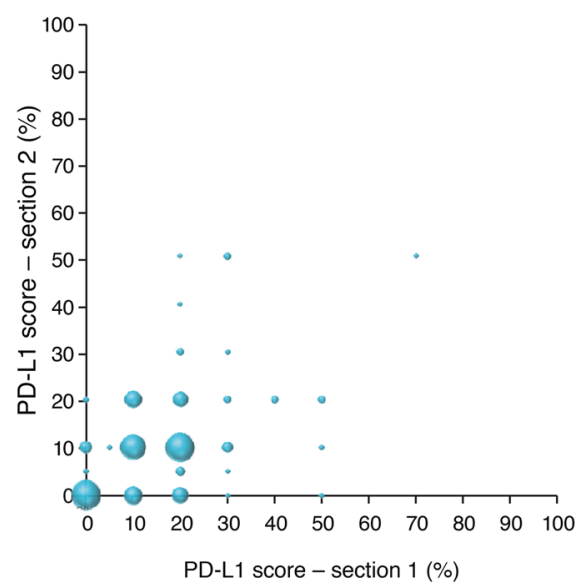

Fig. 3 Correlation in PD-L1 staining between two sections from the same tumor block. Sample size of 200 NSCLC cases. Using the VENTANA PD-L1 (SP263) assay with the VENTANA OptiView DAB IHC detection kit on the automated VENTANA BenchMark ULTRA platform. IC: tumor-infiltrating immune cells; NSCLC: non-small cell lung cancer; PD-L1: programmed cell death ligand-1; TC: tumor cells

to understand the impact of tissue sampling variability on patients' PD-L1 classification. Our study analyzed PD-L1 expression in 15 tumor samples from three indications (NSCLC, HNSCC or UC) as well as in a large, separate cohort of 200 NSCLC samples, and is the first study of PD-L1 heterogeneity using the VENTANA SP263 assay. In the analysis of TCs, we showed high intra-block and intra-case concordance in PD-L1 classification (above or below the cut-off value) across all applied cut-offs and for both sets of samples. Our findings are consistent with previously published data [24, 25], and give a high level of confidence in the reproducibility of TC scoring across the depth of the tumor.

Table 5 Intra-case concordance (OPA) in PD-L1 classification at various applied cut-offs

\begin{tabular}{llll}
\hline \multirow{2}{*}{$\begin{array}{l}\text { Applied } \\
\text { Cut-off }\end{array}$} & \multicolumn{3}{l}{ Concordance (OPA), \% } \\
\cline { 2 - 4 } & NSCLC & HNSCC & UC \\
\hline TC PD-L1 staining & & 100 & 100 \\
$\geq 50 \%$ & 80 & 100 & 100 \\
$\geq 25 \%$ & 100 & 100 & 100 \\
$\geq 10 \%$ & 100 & 100 & 100 \\
$\geq 1 \%$ & 100 & & \\
IC PD-L1 staining & & 100 & 100 \\
$\geq 25 \%$ & 100 & 80 & 100 \\
$\geq 10 \%$ & 60 & 100 & 80 \\
$\geq 5 \%$ & 80 & 80 & 60 \\
$\geq 1 \%$ & 100 &
\end{tabular}

Fifteen NSCLC, HNSCC or UC cases (five cases per indication)

HNSCC head and neck squamous cell carcinoma, $I C$ tumor-infiltrating immune cell, NSCLC non-small cell lung cancer, OPA overall percentage agreement, PD-L1 programmed cell death ligand-1, TC tumor cell, UC urothelial carcinoma
The results from the analysis of PD-L1 expression in ICs were not as consistent as those for TCs, with a good to moderate intra-block and intra-case agreement across the applied cut-offs for the 15 NSCLC, HNSCC or UC samples. Despite this increased variability, the intrablock and intra-case OPA for ICs were $100 \%$ at the $\geq 25 \%$ cut-off. Whilst only one sample (a UC case) was scored above $25 \%$ for ICs, the $100 \%$ OPA reflects the fact that there were no large differences in IC scoring within or between blocks for any of the three indications. The $\geq 25 \%$ cut-off is the approved value for the IC component of the scoring algorithm used with the VENTANA PD-L1 (SP263) assay for identifying UC patients most likely to respond to durvalumab $[4,28]$ and the reproducibility in this small dataset supports the use of this cut-off. In line with these data, intra-block PD-L1 expression was also more variable in ICs than in TCs in the larger NSCLC sample set. The PPA values reported varied from 14.3 to $81.6 \%$; however, the two lowest PPA values at the $\geq 50 \%$ (14.3\%) and $\geq 25 \%$ (17.9\%) cut-offs could be driven by the fact that very few cases were scored above these two cut-off values. The increased intra-case variability in PD-L1 expression in ICs is consistent with a recent study in NSCLC by Rehman et al., who also speculated that the low numbers of PD-L1-expressing ICs may have affected their results [23]. Moreover, the proportion of PD-L1-expressing ICs may depend on the level of infiltration of immune cells into the tumor microenvironment. This may differ between different sections of the tumor, therefore contributing to the observed heterogeneity of IC PD-L1 expression. Variability in IC scoring may also be due to a pathologist's technical ability in scoring ICs. Studies have noted that IC scoring is more variable than TC scoring when 
different pathologists assess identical sections [23, 37], suggesting a need for more extensive training of pathologists specifically on scoring of ICs. IC results in NSCLC should not be extrapolated to more immunogenic cancers such as UC, where there are generally higher proportions of patients with high IC PD-L1 expression (e.g. in the study by Massard et al. using the VENTANA SP263 assay, 45\% of screened UC patients were found to be PD-L1-positive on the basis of IC expression, using a $25 \%$ cut-off [38]).

Our study investigated PD-L1 expression using only the VENTANA PD-L1 (SP263) assay. Similar studies have been carried out using the other approved PD-L1 assays and have been published by the US Food and Drug Administration (FDA) as part of the approval process for each assay (Table 6) [24-27]. PD-L1 expression in TCs has been assessed with the Dako PD-L1 IHC 22C3 PharmDx (intra-block and intra-case concordance: both $100 \%$ at the $\geq 50 \%$ cut-off, in NSCLC) [24] and the Dako PD-L1 IHC 28-8 PharmDx assay (intra-case concordance: $94 \%$ each at the $\geq 1 \%, \geq 5 \%$ and $\geq 10 \%$ cut-offs, in NSCLC) [25]. PD-L1 expression has been assessed using the VENTANA PD-L1 (SP142) assay for ICs in UC (intra-block and intra-case concordance: 100 and $91 \%$, respectively, at the $\geq 5 \%$ cut-off) [27] and for TCs and ICs in NSCLC (intra-block and intra-case concordance: 96 and 81\%, respectively, at the $\geq 50 \%$ TC or $\geq 10 \%$ IC cut-offs) [26] (Table 6) [24-27]. Our data are broadly consistent with these reports, supporting the notion that a patient's TC PD-L1 classification is unlikely to be altered under routine clinical sampling protocols. This is further supported by the Rehman et al. study, which showed minimal intra-case heterogeneity in PD-L1 staining of TCs in 35 NSCLC cases, and suggested that staining one block of a tumor should be enough to represent the entire tumor [23].

A notable strength of our study lies in the analysis of two different sections from the same tumor that were cut 7 months apart (for the 200 NSCLC cases). This mimics what might occur in the clinical setting, where an additional section may be requested from the same tissue block several months later. The high concordance observed in the analysis of TCs here gives a high level of confidence in the reliability of PD-L1 scoring in the real-life clinical situation.

Moreover, our study investigated the consistency in PD-L1 scoring of both TCs and ICs, and using a wide range of clinically relevant cut-offs. The cut-offs were chosen based on the diagnostic algorithms that have been approved or are currently being investigated for the different PD-L1 diagnostic assays and anti-PD-1 / anti-PD-L1 therapies (Table 1) $[4,8,10-13,17,19-22,30-32]$.

One limitation of our study is the fact that the FFPE samples used came from large tumor resections instead of biopsies, thus may not be representative of all clinical samples. This was done for practical reasons, as a large amount of tissue was required (to cut 51 sections per sample), which could not have been achieved from a small biopsy. Whether the PD-L1 status of a tumor would vary depending on the sample type (cytology vs

Table 6 Data on intra-block and intra-case concordance in PD-L1 classification, from publicly available FDA documents ${ }^{a}$

\begin{tabular}{|c|c|c|c|c|}
\hline Assay & $\begin{array}{l}\text { TC PD-L1 staining } \\
\% \text { OPA (\% cut-off) }\end{array}$ & $\begin{array}{l}\text { IC PD-L1 staining } \\
\% \text { OPA (\% cut-off) }\end{array}$ & $\begin{array}{l}\text { TC or IC PD-L1 staining } \\
\% \text { OPA (\% cut-off) }\end{array}$ & $\mathrm{n}$ \\
\hline \multicolumn{5}{|c|}{ Intra-block concordance in PD-L1 classification } \\
\hline \multicolumn{5}{|l|}{ Dako 22C3 } \\
\hline NSCLC [24] & $100 \%(\geq 50 \%)$ & - & - & 20 \\
\hline Dako 28-8 [25] & - & - & - & \\
\hline \multicolumn{5}{|l|}{ VENTANA SP142 } \\
\hline NSCLC [26] & - & - & $96 \%(\geq 50 \%$ TC or $\geq 10 \%$ IC) & 24 \\
\hline UC [27] & - & $100 \%(\geq 5 \%)$ & - & 8 \\
\hline \multicolumn{5}{|c|}{ Intra-case concordance in PD-L1 classification } \\
\hline \multicolumn{5}{|l|}{ Dako 22C3 } \\
\hline NSCLC [24] & $100 \%(\geq 50 \%)$ & - & - & 20 \\
\hline \multicolumn{5}{|l|}{ Dako 28-8 } \\
\hline NSCLC [25] & $94 \%(\geq 1 \% ; \geq 5 \% ; \geq 10 \%)$ & - & - & 16 \\
\hline \multicolumn{5}{|l|}{ VENTANA SP142 } \\
\hline NSCLC [26] & - & - & $81 \%(\geq 50 \%$ TC or $\geq 10 \%$ IC) & 27 \\
\hline UC [27] & - & $91 \%(\geq 5 \%)$ & - & 22 \\
\hline
\end{tabular}

${ }^{\mathrm{a} S u m m a r y}$ of Safety and Effectiveness Data (SSED)

FDA Food and Drug Administration, IC tumor-infiltrating immune cell, NSCLC non-small cell lung cancer, OPA overall percentage agreement, $P D-L 1$ programmed cell death ligand-1, TC tumor cell, UC urothelial carcinoma 
biopsy vs resection) is unknown. A number of studies have investigated concordance in PD-L1 expression between different types of samples using validated FDA approved PD-L1 tests [39-41]. Ilie et al. reported discordance of $19 \%$ between TC scoring in resections and biopsies, with notably higher discordance when IC scoring was also taken into account. This study used the VENTANA PD-L1 (SP142) assay, which has shown lower analytical sensitivity than SP263 [42, 43]. Skov et al. and Heymann et al. both found strong concordance between resections and small biopsies and/or cytology samples using the Dako PD-L1 IHC 22C3 PharmDx and/or PD-L1 IHC 28-8 PharmDx assays [40, 41], which have shown similar sensitivity to SP263 $[29,42]$.

A second limitation of our study was the small sample size of HNSCC and UC cases analyzed (only five cases of each). This may be too small a dataset to confidently draw any conclusions about these indications specifically; however, the results from the NSCLC small intra-block and intra-case study are supported by those from the much larger NSCLC dataset, giving confidence that our findings, particularly those relating to PD-L1 staining of TCs, can be applied across indications.

Thirdly, the scoring of PD-L1 expression in our study was carried out by a single pathologist. This approach was taken to allow determination of intra-block and intra-case agreement without confounding variables. However, in clinical practice samples may be scored by different pathologists, and it would, therefore, be important to establish whether inter-pathologist variability would impact the results.

\section{Conclusions}

Our study showed high intra-block and intra-case concordance in TC PD-L1 classification with the VENTANA PD-L1 (SP263) assay, at various applied cut-offs. These data provide confidence in use of this assay to determine a patient's TC PD-L1 classification, as the results were consistent across the depth of the tumor block and between resections taken from different areas of the tumor. Although more variable than TC staining, consistent IC PD-L1 classification was also observed within and between tumor blocks for most patients.

These are important data to have in hand as the value of biomarker (PD-L1) testing in immunotherapy becomes clearer, and suggest that PD-L1 classification based on the analysis of a single tumor section can be used confidently to inform treatment decisions.

\section{Additional file}

Additional file 1: PD-L1 scoring of 15 NSCLC, HNSCC or UC cases. (DOCX $22 \mathrm{~kb}$ )

\section{Abbreviations}

Cl: Confidence interval; CLIA: Clinical Laboratory Improvement Amendments; FDA: Food and Drug Administration; FFPE: Formalin-fixed, paraffin-embedded; $\mathrm{H} \& \mathrm{E}$ : Hematoxylin and eosin; HNSCC: Head and neck squamous cell carcinoma; IC: Tumor-infiltrating immune cells; NPA: Negative percentage agreement; NSCLC: Non-small cell lung cancer; OPA: Overall percentage agreement; PD-1: Programmed cell death-1; PD-L1: Programmed cell death ligand-1; PPA: Positive percentage agreement; TC: Tumor cell; UC: Urothelial carcinoma

\section{Acknowledgments}

Pathology and PD-L1 interpretation was performed by Professor Gareth Williams (BSc MBChB PhD FRCPath FLSW; Oncologica UK Ltd., Cambridge, UK). Medical writing and editorial assistance were provided by Lietta Nicolaides, $\mathrm{PhD}$, of Cirrus Communications (Ashfield Healthcare, Macclesfield, UK) and was funded by AstraZeneca.

\section{Funding}

This study was sponsored by AstraZeneca. The sponsor contributed to the design and implementation of the study, collection, analysis and interpretation of data, and writing of the report. The authors had final responsibility for the decision to submit for publication.

\section{Availability of data and materials}

The data generated during this study are included in this published article (and its additional files). The raw datasets analyzed during the study are available from the corresponding author on reasonable request.

\section{Authors' contributions}

PS, CB and JW were involved in study design. Data acquisition was carried out by PS and NL; data analysis and interpretation was carried out by PS, MS and MJR. All authors reviewed and approved the final manuscript.

\section{Ethics approval and consent to participate}

All samples were commercially acquired from the following sources: Avaden, Asterand, ProteoGenex, and Tissue Solutions. AstraZeneca has a governance framework and processes in place to ensure that commercial sources have appropriate patient consent and ethical approval in place for collection of the samples for research purposes, including use by for-profit companies. The AstraZeneca Biobank in the UK is licensed by the Human Tissue Authority (Licence No. 12109) and has National Research Ethics Service Committee (NREC) approval as a Research Tissue Bank (RTB) (REC No 17/NW/0207), which covers the use of the samples for this project.

\section{Consent for publication}

Not applicable; no individual person's data presented.

\section{Competing interests}

PS, MS, NL, CB and JW are employees of AstraZeneca and hold stocks or shares in AstraZeneca. MJR is an employee of AstraZeneca. MCR is an employee of Medlmmune LLC and holds stocks or shares in AstraZeneca.

\section{Publisher's Note}

Springer Nature remains neutral with regard to jurisdictional claims in published maps and institutional affiliations.

\section{Author details}

${ }^{1}$ Precision Medicine Laboratories, Precision Medicine and Genomics, IMED Biotech Unit, AstraZeneca, HODGKIN, C/O B310 Cambridge Science Park, Milton Road, Cambridge CB4 OWG, UK. ${ }^{2}$ Oncology Companion Diagnostics Unit, Precision Medicine and Genomics, IMED Biotech Unit, AstraZeneca, Cambridge, UK. ${ }^{3}$ Translational Sciences, Research, Medlmmune, Gaithersburg, MD, USA.

Received: 19 January 2018 Accepted: 5 July 2018

Published online: 24 July 2018

\section{References}

1. Zou W, Chen L. Inhibitory B7-family molecules in the tumour microenvironment. Nat Rev Immunol. 2008;8:467-77. 
2. Pardoll DM. The blockade of immune checkpoints in cancer immunotherapy. Nat Rev Cancer. 2012;12:252-64.

3. Postow MA, Callahan MK, Wolchok JD. Immune checkpoint blockade in cancer therapy. J Clin Oncol. 2015;33:1974-82.

4. Powles T, O'Donnell PH, Massard C, Arkenau HT, Friedlander TW, Hoimes CJ, et al. Efficacy and safety of durvalumab in locally advanced or metastatic urothelial carcinoma: updated results from a phase 1/2 open-label study. JAMA Oncol. 2017:3:e172411.

5. Reck M, Rodriguez-Abreu D, Robinson AG, Hui R, Csoszi T, Fulop A, et al. Pembrolizumab versus chemotherapy for PD-L1-positive non-small-cell lung cancer. N Engl J Med. 2016;375:1823-33.

6. Herbst RS, Baas P, Kim DW, Felip E, Perez-Gracia JL, Han JY, et al. Pembrolizumab versus docetaxel for previously treated, PD-L1-positive, advanced non-small-cell lung cancer (KEYNOTE-010): a randomised controlled trial. Lancet. 2016:387:1540-50.

7. Larkins E, Blumenthal GM, Yuan W, He K, Sridhara R, Subramaniam S, et al. FDA approval summary: pembrolizumab for the treatment of recurrent or metastatic head and neck squamous cell carcinoma with disease progression on or after platinum-containing chemotherapy. Oncologist. 2017;22:873-8.

8. Borghaei H, Paz-Ares L, Horn L, Spigel DR, Steins M, Ready NE, et al. Nivolumab versus docetaxel in advanced nonsquamous non-small-cell lung cancer. $N$ Engl J Med. 2015;373:1627-39.

9. Brahmer J, Reckamp KL, Baas P, Crinò L, Eberhardt WE, Poddubskaya E, et al. Nivolumab versus docetaxel in advanced squamous-cell non-small-cell lung cancer. N Engl J Med. 2015;373:123-35.

10. Ferris RL, Blumenschein G Jr, Fayette J, Guigay J, Colevas AD, Licitra L, et al. Nivolumab for recurrent squamous-cell carcinoma of the head and neck. N Engl J Med. 2016;375:1856-67.

11. Sharma P, Retz M, Siefker-Radtke A, Baron A, Necchi A, Bedke J, et al. Nivolumab in metastatic urothelial carcinoma after platinum therapy (CheckMate 275): a multicentre, single-arm, phase 2 trial. Lancet Oncol. 2017;18:312-22

12. Rosenberg JE, Hoffman-Censits J, Powles T, van der Heijden MS, Balar AV, Necchi A, et al. Atezolizumab in patients with locally advanced and metastatic urothelial carcinoma who have progressed following treatment with platinumbased chemotherapy: a single-arm, multicentre, phase 2 trial. Lancet. 2016;387: 1909-20.

13. Fehrenbacher L, Spira A, Ballinger M, Kowanetz M, Vansteenkiste J, Mazieres J, et al. Atezolizumab versus docetaxel for patients with previously treated non-small-cell lung cancer (POPLAR): a multicentre, open-label, phase 2 randomised controlled trial. Lancet. 2016;387:1837-46.

14. Rittmeyer A, Barlesi F, Waterkamp D, Park K, Ciardiello F, von Pawel J, et al. Atezolizumab versus docetaxel in patients with previously treated nonsmall-cell lung cancer (OAK): a phase 3, open-label, multicentre randomised controlled trial. Lancet. 2017;389:255-65.

15. Kaufman HL, Russell J, Hamid O, Bhatia S, Terheyden P, D'Angelo SP, et al. Avelumab in patients with chemotherapy-refractory metastatic Merkel cell carcinoma: a multicentre, single-group, open-label, phase 2 trial. Lancet Oncol. 2016;17:1374-85.

16. Rizvi NA, Mazières J, Planchard D, Stinchcombe TE, Dy GK, Antonia SJ, et al. Activity and safety of nivolumab, an anti-PD-1 immune checkpoint inhibitor, for patients with advanced, refractory squamous non-small-cell lung cancer (CheckMate 063): a phase 2, single-arm trial. Lancet Oncol. 2015;16:257-65.

17. Bauml J, Seiwert TY, Pfister DG, Worden F, Liu SV, Gillbert J, et al. Pembrolizumab for platinum- and cetuximab-refractory head and neck cancer: results from a single-arm, phase II study. J Clin Oncol. 2017;35:1542-9.

18. Chow LQ, Haddad R, Gupta S, Mahipal A, Mehra R, Tahara M, et al. Antitumor activity of pembrolizumab in biomarker-unselected patients with recurrent and/or metastatic head and neck squamous cell carcinoma: results from the phase Ib KEYNOTE-012 expansion cohort. J Clin Oncol. 2016;34:3838-45.

19. Ventana Medical Systems. VENTANA PD-L1 (SP263) Assay. Updated 2017 Available from: http://www.ventana.com/ventana-pd-11-sp263-assay-2/. Accessed May 2017

20. Dako. PD-L1 IHC 28-8 pharmDx. October 2015. Available from: http://www. accessdata.fda.gov/cdrh_docs/pdf15/P150025c.pdf. Accessed 10 Aug 2016.

21. Dako. PD-L1 IHC 22C3 pharmDx. September 2015. Available from: http:// www.accessdata.fda.gov/cdrh_docs/pdf15/P150013c.pdf. Accessed 10 Aug 2016.

22. VENTANA. VENTANA PD-L1 (SP142) Assay. Updated 2016. Available from: http://www.ventana.com/product/1827?type=2357. Accessed May 2017.
23. Rehman JA, Han G, Carvajal-Hausdorf DE, Wasserman BE, Pelekanou V, Mani NL, et al. Quantitative and pathologist-read comparison of the heterogeneity of programmed death-ligand 1 (PD-L1) expression in non-small cell lung cancer. Mod Pathol. 2017:30:340-9.

24. Food and Drug Administration (FDA). Dako 22C3 summary of safety and effectiveness data. 2015. Available from: http://www.accessdata.fda.gov/ cdrh_docs/pdf15/p150013b.pdf. Accessed May 2017.

25. Food and Drug Administration (FDA). Dako 28-8 summary of safety and effectiveness data. October 2015. Available from: http://www.accessdata.fda. gov/cdrh_docs/pdf15/P150025b.pdf. Accessed May 2017.

26. Food and Drug Administration (FDA). Ventana SP142 summary of safety and effectiveness data. October 2016. Available from: https://www.access data.fda.gov/cdrh_docs/pdf16/p160006b.pdf. Accessed May 2017.

27. Food and Drug Administration (FDA). Ventana SP142 summary of safety and effectiveness data. May 2016. Available from: http://www.accessdata.fda. gov/cdrh_docs/pdf16/P160002b.pdf. Accessed May 2017

28. VENTANA. VENTANA PD-L1 (SP263) Assay. Updated April 2017. Available from: https://www.accessdata.fda.gov/cdrh_docs/pdf16/p160046c.pdf. Accessed Oct 2017

29. Ratcliffe MJ, Sharpe A, Midha A, Barker C, Scott M, Scorer P, et al. Agreement between programmed cell death ligand-1 diagnostic assays across multiple protein expression cut-offs in non-small cell lung cancer. Clin Cancer Res. 2017;23:3585-91.

30. Rebelatto MC, Midha A, Mistry A, Sabalos C, Schechter N, Li X, et al. Development of a programmed cell death ligand-1 immunohistochemical assay validated for analysis of non-small cell lung cancer and head and neck squamous cell carcinoma. Diagn Pathol. 2016;11:95.

31. Merck Sharp \& Dohme. Keytruda (pembrolizumab) highlights of prescribing information. Updated May 2017. Available from: https://www.merck.com/ product/usa/pi_circulars/k/keytruda/keytruda_pi.pdf. Accessed 12 May 2017.

32. Bellmunt J, de Wit R, Vaughn DJ, Fradet Y, Lee JL, Fong L, et al. Pembrolizumab as second-line therapy for advanced urothelial carcinoma. N Engl J Med. 2017; 376:1015-26.

33. Cohen E, Harrington K, Le Tourneau C, Dinis J, Licitra L, Ahn M-J, et al. Pembrolizumab vs standard of care for recurrent or metastatic head and neck squamous cell carcinoma: Phase 3 KEYNOTE-040 trial. Oral presentation at the European Society for Medical Oncology (ESMO) Annual Meeting, Madrid, Spain, September 8-12, 2017 (Abstr. LBA45).

34. Food and Drug Administration (FDA). Guidance for industry and FDA staff. Statistical guidance on reporting results from studies evaluating diagnostic tests. March 13, 2007. Available from: http://www.fda.gov/downloads/ MedicalDevices/DeviceRegulationandGuidance/GuidanceDocuments/ ucm071287.pdf. Accessed Apr 2017.

35. Clopper CJ, Pearson ES. The use of confidence or fiducial limits illustrated in the case of the binomial. Biometrika. 1934;26:404-13.

36. Scott M, Ratcliffe MJ, Sharpe A, Barker C, Scorer P, Rebelatto M, et al. Concordance of tumor and immune cell staining with Ventana SP263, Dako 28-8, Dako 22C3 and Ventana SP142 PD-L1 immunohistochemistry assays in NSCLC patient samples. Poster presentation at the ASCO-SITC Clinical Immuno-Oncology Symposium, Orlando, FL, USA, February 23-25, 2017.

37. Scheel AH, Dietel M, Heukamp LC, Johrens K, Kirchner T, Reu S, et al. Harmonized PD-L1 immunohistochemistry for pulmonary squamous-cell and adenocarcinomas. Mod Pathol. 2016:29:1165-72.

38. Massard C, Gordon MS, Sharma S, Rafii S, Wainberg ZA, Luke J, et al. Safety and efficacy of durvalumab (MEDI4736), an anti-programmed cell death ligand-1 immune checkpoint inhibitor, in patients with advanced urothelial bladder cancer. J Clin Oncol. 2016;34:3119-25.

39. Ilie M, Long-Mira E, Bence C, Butori C, Lassalle S, Bouhlel L, et al. Comparative study of the PD-L1 status between surgically resected specimens and matched biopsies of NSCLC patients reveal major discordances: a potential issue for anti-PD-L1 therapeutic strategies. Ann Oncol. 2016;27:147-53.

40. Skov BG, Skov T. Paired comparison of PD-L1 expression on cytologic and histologic specimens from malignancies in the lung assessed with PD-L1 IHC 28-8pharmDx and PD-L1 IHC 22C3pharmDx. Appl Immunohistochem Mol Morphol. 2017;25:453-9.

41. Heymann JJ, Bulman WA, Swinarski D, Pagan CA, Crapanzano JP, Haghigh $M$, et al. PD-L1 expression in non-small cell lung carcinoma: comparison among cytology, small biopsy, and surgical resection specimens. Cancer. 2017;125:896-907.

42. Hirsch FR, McElhinny A, Stanforth D, Ranger-Moore J, Jansson M, Kulangara $\mathrm{K}$, et al. PD-L1 immunohistochemistry assays for lung cancer: results from 
phase 1 of the blueprint PD-L1 IHC assay comparison project. J Thorac Oncol. 2017;12:208-22.

43. Scott M, Ratcliffe MJ, Sharpe A, Barker C, Scorer P, Rebelatto M, et al. Concordance of tumor cell (TC) and immune cell (IC) staining with

Ventana SP142, Ventana SP263, Dako 28-8 and Dako 22C3 PD-L1 IHC tests in NSCLC patient samples. J Clin Oncol. 2017;35(15_suppl):e14503.

Ready to submit your research? Choose BMC and benefit from:

- fast, convenient online submission

- thorough peer review by experienced researchers in your field

- rapid publication on acceptance

- support for research data, including large and complex data types

- gold Open Access which fosters wider collaboration and increased citations

- maximum visibility for your research: over $100 \mathrm{M}$ website views per year

At BMC, research is always in progress.

Learn more biomedcentral.com/submissions 